\title{
ANNA FORNALCZYK-LIPSKA
}

https://orcid.org/0000-0002-4393-3922

Uniwersytet Warszawski

a.fornalczyk@uw.edu.pl

\section{PAMIĘĆ 0 TŁUMACZU.}

\section{SYLWETKI TŁUMACZY LITERATURY}

W NEKROLOGACH I WSPOMNIENIACH POŚMIERTNYCH

\section{Abstract}

\section{Remembering Literary Translators: A Content Analysis of Their Obituaries}

Obituaries, being representative of collective memory, reveal not only whose lives we choose to remember (to allude to the suggestive title of Fowler, Bielsa 2007), but also what values and achievements we hold in high regard. Among others, obituaries of members of the following professions have been the subject of research: librarians (Dilevko, Gottlieb 2004), psychologists (Kinnier et al. 1994) and academics (Hamann 2016). The present paper focuses on obituaries devoted to literary translators, published in academic journals and literary and cultural magazines in 2000-2017.

Content analysis, deployed as the main research method in this paper, proved to be useful in identifying references to specific values, typical of translators' lives and work. As a result, a classification of the most frequently mentioned translators' characteristics and achievements was prepared. Recurrent characteristics presented translators as competent, hard-working, good friends, intelligent and independent-minded, while their top achievements included prizes and awards, prestigious friendships and acquaintances, and merits for establishing closer relations between nations. The vast majority of texts were positive-factual or personal-emotional in character, but a few included criticalfactual remarks, mainly on translators' character and the clash of one's ideals or ambitions with reality. Attention has been drawn to multidirectional careers of most translators. In the last part of the article, obituaries were described as a cultural phenomenon in the context of memory culture, with a special emphasis on the categories of the communicator and the addressee, as well as the language. 
Slowa klucze: przekład, pamięć, tłumacze, nekrologi

Key words: translation, memory, translators, obituaries

W artykule poświęconym nekrologom rosyjskim w ich radzieckiej odmianie Tadeusz Klimowicz pisze, jak pomocne mogą być teksty żałobne w określeniu znaczenia i zasług pisarzy dla kultury:

O randze zmarłego świadczyła z całą pewnością liczba nadawców (...). Dzięki temu nie mamy już żadnych wątpliwości, że Aleksiej Niedogonow z 40 podpisami w „Litieraturnoj gazietie” (1948 nr 22) jest o jedną trzecią lepszym pisarzem od Borisa Jaglinga - 33 podpisy (1948 nr 17), ale z kolei jest o połowę gorszy od Nikołaja Tichonowa, o którego wielkości zaświadczyło 99 osób (1979 nr 2) itd. (Klimowicz 1996: 184-185).

Oczywiście opisana sytuacja dotyczy nekrologów instytucjonalnych, silnie uwarunkowanych partyjno-państwową ideologią, ale pokazuje, w jakim stopniu teksty żałobne stanowią dokument określonych czasów i obyczajów, mówiąc niekiedy więcej o żywych niż o zmarłych. Jako teksty o śmierci, pisane w kontekście spraw ostatecznych, są silnie nacechowane emocjonalnie i aksjologicznie, ujawniając, jakie cechy, wartości i osiągnięcia zmarłych są uznane za ważne, godne utrwalenia i przekazania pamięci współczesnych, a także dalszych pokoleń. Celem niniejszego artykułu jest próba odpowiedzi na pytanie, w jaki sposób nekrologi i wspomnienia pośmiertne zamieszczane na łamach periodyków naukowych, literackich i kulturalnych kształtują pamięć o tłumaczach literatury.

Bridget Fowler (2007) przekonująco argumentuje, że nekrologi (rozumiane nie jako „ogłoszone w prasie zawiadomienia o zgonie”, ale w szerszym znaczeniu - jako „,artykuły omawiające życie i dzieło osoby zmarłej”, por. Sławiński 2002: 338) mogą się okazać cenne jako zasób wiedzy dotyczącej kapitału społecznego i znaczenia zmarłej osoby w społeczeństwie, dlatego są ważnymi składowymi pamięci zbiorowej czy społecznej (Fowler 2007: 25). Nieodłączny związek nekrologów z pamięcią społeczną podkreśla też Barbara Szacka, pisząc, że rolą tej ostatniej jest między innymi ,przekaz wartości i wzorów zachowań pożądanych. Wartości i wzory przechowywane w pamięci społecznej odnoszą się do sfery życia publicznego - mówią o tym, jaki powinien być dobry obywatel i jak powinien zachowywać się członek danej 
wspólnoty” (Szacka 2000: 54). Publicznie dostępne teksty wspomnieniowe upamiętniają więc zmarłych, o których chcemy pamiętać jako społeczeństwo, pomijając tych, o których pamiętać nie chcemy, a będąc nośnikami pamięci społecznej, ujawniają, jakie wartości i osiągnięcia cenimy. W obszernym opracowaniu Obituaries in American Culture (Hume 2000) przedmiotem szczegółowych studiów stały się wartości cenione w społeczeństwie amerykańskim w trzech okresach historycznych. Autorka wykazuje, że sposób upamiętnienia indywidualnych obywateli daje publiczny wyraz wartościom cenionym przez całe społeczeństwo - dziewiętnastowieczne nekrologi opisywały charakter osoby zmarłej, dwudziestowieczne - jej pracę i dorobek. Odwrotną relację między indywidualnym i zbiorowym wymiarem pamięci omawiają Einat Lachover i Dalia Gavriely-Nuri (2011), pokazując, w jaki sposób nekrologi kształtują narodową tożsamość Izraelczyków. Nekrologi ujawniają wartości cenione przez daną społeczność nie tylko na płaszczyźnie narodowej, ale i zawodowej. Wśród grup zawodowych, których nekrologi analizowano w ostatnich latach w czasopismach naukowych, znaleźli się między innymi bibliotekarze (Dilevko, Gottlieb 2004), psychologowie (Kinnier et al. 1994) i akademicy (Macfarlane, Chan 2014; Hamann 2016). Dilevko i Gottlieb zauważają rozdźwięk między społecznym postrzeganiem zawodu bibliotekarza a jego odzwierciedleniem w nekrologach zamieszczanych w „The New York Times”, sugerując, że podkreślanie wybitnych osiągnięć przedstawicieli tej profesji zniekształca jej obraz, przesłaniając zasługi „zwykłych” bibliotekarzy, na co dzień służących danej społeczności. Richard Kinnier i inni przedstawiają modelowy profil demograficzny psychologów upamiętnionych w „American Psychologist” oraz wymieniają najczęściej pojawiające się w ich nekrologach wartości, wśród których najwyżej ceniono niezależność, przyjaźń i pracowitość. Z kolei Hamann sytuuje nekrologi wykładowców akademickich w perspektywie oceny ich życia przez kolegów (postrzegając ,uczczenie jednego z nas” jako główną funkcję tego typu tekstów) i odkrywa konkretne ramy narracyjne (odwołanie do skryptów wrodzonych talentów i osiągnięć, sprawczości i wewnętrznej motywacji, kategoryzacji według wiedzy i stanowiska), nakazujące uwzględnienie bądź pominięcie określonych elementów biografii. Macfarlane i Chan analizują przedstawione w nekrologach cechy i osiągnięcia akademików w kontekście intelektualnego przywództwa, wykraczającego poza ramy formalnych struktur kierowniczych. Warto także wspomnieć artykuł Hannelore Gomez (2017), w którym autorka dokonała analizy ilościowej danych demograficznych zamieszczonych w nekrologach ,zwykłych” tłumaczy 
(często amatorów), pisanych przez „zwykłych” ludzi (przyjaciół, rodziny) na tle społeczności stanu Ohio. Autorka omawia społeczne postrzeganie roli tłumacza jako osoby służącej krajowi i lokalnej społeczności, odmienne od perspektywy krytyków i teoretyków przekładu.

We wszystkich wyżej wymienionych pracach dominuje przekonanie, że nekrolog stanowi wyróżnienie i jest formą nobilitacji osoby ważnej dla danej społeczności zawodowej lub dla ogółu społeczeństwa. W niniejszym artykule zostaną omówione nekrologi i wspomnienia dotyczące tłumaczy literatury opublikowane w latach 2000-2017 na łamach czasopism naukowych, literackich i kulturalnych w Polsce, a więc adresowane do specjalistów i elity intelektualnej. Wyszukiwanie artykułów przeprowadzono na podstawie katalogu głównego Biblioteki Narodowej, w bazie artykułów z czasopism polskich przy zastosowaniu haseł: temat/słowo z opisu „tłumacz*” i słowo z opisu „wspomnienie” lub „nekrolog”. Po odrzuceniu powtórzeń oraz wyników nieadekwatnych, a także wywiadów i tekstów pisanych więcej niż 10 lat od śmierci danej osoby, pozostało 50 tekstów wspomnieniowych.

Pewnych trudności metodologicznych przysporzył fakt, że kariera zawodowa większości tłumaczy przebiegała wielotorowo. Dla przykładu, Stanisław Barańczak, ,poeta, tłumacz, krytyk literacki i historyk literatury, eseista" (Barańczak Stanisław, Encyklopedia PWN online), przyznał w jednym z wywiadów: „Gdyby brać pod uwagę wyłącznie proporcje czasowe, można by powiedzieć, że jestem właściwie tłumaczem, natomiast poetą tylko bywam" (Stanisław Barańczak, Culture.pl). Może też zdarzyć się, że dorobek pisarski przesłoni całkowicie znaczny niekiedy dorobek translatorski - tak stało się z Czesławem Miłoszem, w bazie Biblioteki Narodowej opisanym wyłącznie deskryptorem ,pisarze polscy” i nieuwzględnionym w niniejszej analizie. Choć sam o sobie powiedział: „Tłumaczyłem zawsze bardzo dużo i z rożnych języków - i zawsze mnóstwo się ucząc. Mój poetycki warsztat byłby chudy, gdyby nie był odżywiany ciągle nowymi obrazami, nawet, powiedziałbym, nowymi cywilizacjami” (Miłosz 2006: 377), a jego działalność przekładowa doczekała się obszernego opracowania (Heydel 2013), to w nekrologach mu poświęconych brak o niej jakiekolwiek wzmianki. Określenie, czy tłumaczenie stanowiło główny, równorzędny czy poboczny rodzaj działalności danej osoby, wymagałoby w wielu przypadkach oddzielnego, dogłębnego studium, dlatego do korpusu analizowanych tekstów włączono te artykuły, w których wystąpiły konkretne odniesienia do przekładu literatury, pomijając te, które ograniczały się jedynie do wzmianki, że dana osoba była tłumaczem. W analizie wzięto pod uwagę 35 tłumaczy 
(23 mężczyzn i 12 kobiet). Analizowane teksty wspomnieniowe poświęcone są zarówno tłumaczom bardzo znanym (jak Karl Dedecius czy Stanisław Barańczak), jak i tym zasłużonym przede wszystkim dla społeczności lokalnej (Tomasz Pryll w środowisku sudeckim); translatorom o dorobku niezwykle bogatym (jak Henryk Bereska, który przetłumaczył na język niemiecki ponad 200 dzieł) i tym znanym z przekładu jednej tylko książki (np. Maria Brandysowa, której przekład Obcego Camusa określono jako arcydzieło - Bocheński 2007: 187).

Podstawowym celem analizy było zbadanie, w jaki sposób nekrologi i wspomnienia przedstawiają tłumaczy literatury. Jako główną technikę badawczą zastosowano analizę zawartości według kryteriów opisanych przez Tomasza Gackowskiego i Marcina Łączyńskiego (2009). Stanowi ona przydatne narzędzie w metodologii badania wizerunku w mediach i pozwala na zidentyfikowanie odniesień do konkretnych wartości, charakterystycznych dla życia tłumaczy i ich pracy przekładowej. Po informacjach wstępnych (płeć tłumaczy oraz ewentualne łączenie działalności translatorskiej z inną) przedstawione zostaną wartości (cechy) oraz osiągnięcia najczęściej przypisywane tłumaczom w poszczególnych artykułach. Następnie omówię teksty wspomnieniowe jako zjawisko kulturowe w obszarze kultury pamięci, charakteryzując kategorię nadawcy i odbiorcy oraz język komunikacji nekrologicznej.

Tłumaczkom poświęcono 34\% tekstów. Pojawia się pytanie, dlaczego częściej wspominano tłumaczy? Może to wskazywać na fakt, że kobiety nie cieszą się tak wysokim miejscem w polu przekładu literackiego jak mężczyźni. Udzielenie pełnej odpowiedzi wymagałoby jednak odrębnego opracowania oraz analizy wykraczającej poza ramy niniejszego artykułu, uwzględniającej między innymi procentowy udział kobiet w przekładzie literackim w XX wieku, kulturotwórcze znaczenie ich pracy oraz miejsce w kulturze literackiej. Wszyscy tłumacze z wyjątkiem jednego łączyli działalność translatorską z inną. Wielostronność prac, w które się angażowali, przedstawiono w tabeli 1 . W większości przypadków była to działalność powiązana z literaturą, sztuką i językoznawstwem, czyli twórczość własna, praca naukowo-dydaktyczna i redaktorska oraz krytyka. 
Tabela 1. Wielostronność działań zawodowych tłumaczy literatury

\begin{tabular}{|l|c|}
\hline Rodzaj działalności wg tekstów wspomnieniowych & Liczba tlumaczy \\
\hline pisarz, poeta, dramaturg & 21 \\
\hline edytor, redaktor & 12 \\
\hline naukowiec & 11 \\
\hline eseista, dziennikarz, publicysta & 8 \\
\hline dyrektor, kierownik (głównie instytucji kulturalnych) & 6 \\
\hline krytyk (literatury, sztuki, teatralny) & 5 \\
\hline organizator/animator życia kulturalnego & 2 \\
\hline agent ubezpieczeniowy & 1 \\
\hline dyplomata & 1 \\
\hline geofizyk & 1 \\
\hline urzędniczka/bibliotekarka & 1 \\
\hline producentka, reżyserka & 1 \\
\hline przewodnik sudecki & 1 \\
\hline pracownik biur projektowych & 1 \\
\hline egzegeta/ksiądz & 1 \\
\hline pracownik fizyczny & 1 \\
\hline tłumaczenie jako jedyna działalność & 1 \\
\hline
\end{tabular}

Już na pierwszy rzut oka tłumacze jawią się jako osobowości wszechstronne, otwarte na świat, ludzie z pasją. Działalność przekładowa może, zgodnie z cytowanymi wyżej słowami Miłosza, odżywiać własny warsztat pisarski czy poetycki, stanowiąc istotną gałąź twórczości literackiej danej osoby - dlatego nie dziwi fakt, że w nekrologach większości tłumaczy znalazły się wzmianki o ich twórczości własnej. Z kolei zadanie popularyzacji literatury, w które często angażują się tłumacze, w sposób naturalny łączy się z pracami edytorsko-redaktorskimi. Wysokie miejsce zajmuje także praca naukowo-dydaktyczna, ukazując tłumaczenie jako jeden z przejawów fascynacji danym językiem, związaną z nim literaturą i kulturą. Z pewnością nie bez znaczenia jest także aspekt finansowy - jak wiadomo z opracowań dotyczących thumaczy literatury, tylko w niewielu przypadkach ten rodzaj działalności zapewnia utrzymanie (por. choćby Wasilewska 2012; Szymczak 2013). Niektóre nekrologi wprost odnoszą się do finansów jako czynnika wymuszającego wielotorowość pracy tłumaczy literatury. Agnieszka Brockmann pisze: 
Literatura zawsze była deficytowa. Dedecius, świetnie radzący sobie w komercyjnej firmie, był tego świadomy i dlatego do momentu odejścia na emeryturę traktował swoją pracę literacką jako hobby - uprawiane pokątnie, w chwilach wolnych, podczas uciążliwych podróży służbowych pociągiem lub samolotem (Brockmann 2016: 98, 100).

Niezależność finansowa umożliwiła Dedeciusowi realizację swojej pasji i misji - stworzenie pomostu wzajemnego zrozumienia i pojednania między Polakami a Niemcami przez przekład i popularyzację polskiej literatury w Niemczech. Niekiedy jednak czynnik finansowy wymuszał obniżenie ambicji, jak w przypadku Joanny Guze:

O Trzech Muszkieterach w swoim dorobku przekładowym mówiła tak, jakby się ich wstydziła. Przetłumaczyła na nowo tę popularną powieść wydawaną od półtora wieku w masowych nakładach, bo musiała z czegoś żyć (...) Jednak normą intelektualną i artystyczną był dla Niej poziom Camusa. (...) Uważała, że zadawanie się z Dumasem wymaga usprawiedliwienia (Bocheński 2009: 206).

W analizowanych tekstach wspomnieniowych warunki pracy thumacza ujawniano niejako na marginesie, poświęcając najwięcej uwagi charakterystyce osoby i jej działalności. Najczęściej opisywane wartości (cechy tłumaczy) przedstawiono w tabeli 2 . W odrębnej kolumnie określono liczbę tłumaczy, do których odnosiła się dana wartość.

Tabela 2. Liczba i procent artykułów odnoszących się do poszczególnych wartości

\begin{tabular}{|l|c|c|c|c|}
\hline Wartości / cechy & $\begin{array}{l}\text { Liczba } \\
\text { artykułów }\end{array}$ & $\begin{array}{l}\text { Procent } \\
\text { artykułów }\end{array}$ & $\begin{array}{l}\text { Liczba } \\
\text { tlumaczy }\end{array}$ & $\begin{array}{l}\text { Procent } \\
\text { tlumaczy }\end{array}$ \\
\hline kompetencja & 22 & 44 & 19 & 54 \\
\hline pracowitość & 21 & 42 & 14 & 40 \\
\hline przyjaźn & 20 & 40 & 16 & 46 \\
\hline inteligencja & 19 & 38 & 15 & 43 \\
\hline indywidualizm & 18 & 36 & 12 & 34 \\
\hline energia & 17 & 34 & 14 & 40 \\
\hline staranność & 16 & 32 & 14 & 40 \\
\hline życzliwość & 15 & 30 & 12 & 34 \\
\hline poczucie humoru & 14 & 28 & 11 & 31 \\
\hline skromność & 13 & 26 & 10 & 29 \\
\hline
\end{tabular}


Na pierwszym miejscu znalazła się kompetencja, rozumiana jako wiedza, zdolności, umiejętności, znawstwo przedmiotu. Wartości odnoszące się do tej kategorii wymieniono w niemal połowie tekstów (44\%). Oddzielnie, na czwartej pozycji, zaklasyfikowano zbliżoną do kompetencji kategorię inteligencji (38\% tekstów). Na drugim miejscu uplasowała się pracowitość (42\% tekstów), często opatrywana sugestywnymi dopowiedzeniami: Henryk Bereska „oddawał [się] katorżniczej pracy: tysiące stron przekładów z literatury polskiej” (Kijonka 2005: 28), Stanisław Barańczak był gigantem, wyznaczającym sobie ,pracę nie do wykonania dla przeciętnego człowieka” (Tomsia 2015: 177), zaś Karl Dedecius to „tytan wiedzy i pracowitości” (Kuczyński K. 2016: 10). W wielu przypadkach wspomina się, że tłumacze (nawet ci w podeszłym wieku) pracowali niemal do ostatnich chwil życia. Uzupełnienie kategorii pracowitości stanowi staranność (siódma pozycja, $32 \%$ artykułów), rozumiana jako rzetelność, sumienność, wnikliwość, dociekliwość. Dla przykładu, w nekrologu Aliji Dukanovicia wspomina się, że wstawał w nocy do tekstu jak do dziecka, by go doskonalić (Cirlić-Straszyńska 2009: 125). Z kolei Ziemowit Fedecki, krytyczny wobec swej pracy translatorskiej, ,[n] ad przekładem Triumfu rolnictwa Zabłockiego spędził kilkanaście lat (chyba 18)", nieustannie go ulepszając (Kołodziej 2009: 241).

Niemal na równi z pracowitością ceniona była przyjaźń (40\% tekstów). Wysokie miejsce tej wartości jest najprawdopodobniej związane z tym, iż w większości przypadków (68\%) autor nekrologu lub wspomnienia ujawnił się jako znajomy lub przyjaciel zmarłego. Jako odrębną kategorię potraktowano życzliwość (również serdeczność, ciepło, dobroć) - często związaną z troską o innych tłumaczy czy pisarzy - która znalazła się na ósmej pozycji (30\% tekstów).

Kolejnymi cenionymi cechami były indywidualizm (niezależność, niekonwencjonalność, niezwykłość, pionierskość, wymieniona w 36\% tekstów) oraz energia (34\%) rozumiana jako żywiołowość, żywość, apetyt na życie, nienasycenie, aktywność. Obie okazały się szczególnie istotne w przypadku najwybitniejszych tłumaczy, pozwalając im dokonywać wielkich, pionierskich dzieł. Zwłaszcza ambicje publikacji i popularyzacji mało znanych autorów związane były z intensywnym, czasochłonnym poszukiwaniem wydawcy, wymagały „zbudowania gęstej sieci kontaktów, ich pielęgnacji, łatwości przekonywania i talentu mediatora" (Brockmann 2016: 101). Wgląd w pracę tłumacza promotora czy akuszera książek dają także fragmenty wspomnień o Henryku Beresce, który „był wszędzie: jako tłumacz, jako autor, jako prezenter polskich autorów, popularyzator polskiej kultury" 
(Mieszko-Wiórkiewicz 2005: 72) i który „stał się maszyną do przesiewania polskiego kruszcu duchowego w niemieckie mózgi. Chodził po niemieckich wydawnictwach z polskimi poetami i powieściopisarzami jak po biedzie i molestował redaktorów. Henryk Bereska jest przykładem ludzkiego heroizmu" (Kutz 2005: 133). Wartość ta ma także drugie oblicze: nienasycenia, zachłanności w odniesieniu do pracy translatorskiej, jak u Stanisława Barańczaka, którego charakteryzowały ,apetyt na życie, zdolność do zachwytu i nowych olśnień (...), lekturowe - i pisarskie - nienasycenie, zachłannoś[ć] i rozległoś[ć] zainteresowań” (Illg 2015: 86).

Przedostatnie miejsce ( $28 \%$ tekstów) zajmuje poczucie humoru - warto tu przytoczyć cytat z nekrologu Krystyny Krzemień-Ojak, która

[t]łumaczenie zawsze traktowała jak ,wiedzę radosną”. Z jakim uznaniem i entuzjazmem potrafiła się śmiać, gdy trzeba było przekładać pewne dziś już niespotykane konstrukcje językowe, na przykład występujące w urzędowym języku używanym w Królewcu (przy okazji tłumaczenia biografii Kanta, 2005) bądź w sentencjach Jean-Paula (Dietzsch 2016: 12).

I wreszcie - skromność, cecha, którą Tadeusz Kijonka przedstawił jako nieodłączny komponent wizerunku tłumacza, umiejscawiając ją w szerszym kontekście aksjologicznym jako jedną z wartości cenionych w środowisku wychowawczym:

Wypracował Bereska także własne zasady sztuki przekładu, które sprowadzają się do generalnej reguły, że tlumacz to stuga, który wedle najlepszej wiedzy i z najlepsza wola spetnia jedynie swoja powinność. Nagroda jest dobrze wykonana robota, radość z jej powodzenia, satysfakcja trudu, zmagania się. Te cechy wiązał ze swoim śląskim rodowodem (...). W mowie wrocławskiej w Auli Leopoldińskiej (...) [m]ówił Bereska: W górnoślaskim ,familoku”, wielorodzinnym domu, szanowano pewne cechy, stwarzaty thumacza: kult sumiennej pracy - podstawowa sprawa dla translatora. Nie: puszenie siętym, czego się dokonało - ale: solidnośćpracy. Fuszerka oznaczałaby śmierć. Cierpliwość rozumiała sięsama przez się. Także skromność (Kijonka 2005: 27, 28).

Analiza zawartości tekstów wspomnieniowych ujawniła także inne ciekawe tematy, na przykład źródła motywacji tłumaczy - wątek ten pojawia się w jednej trzeciej artykułów. Tłumaczenie nie jest celem samym w sobie ani jedynie źródłem utrzymania, ale stanowi powołanie, misję, środek do osiągnięcia wyższego celu. Dla przykładu, ks. Marian Wolniewicz traktował przekładanie Biblii w kategoriach przybliżania wiernym Bożego objawienia, 
a więc jako formę realizacji swojego kapłańskiego powołania (Kubski 2006: 151). Z kolei Henryk Bereska podporządkował życie „misji całkowitego oddania nadrzędnej idei przeniesienia rozległych połaci polskiej literatury w język niemiecki”, na co należy patrzeć z perspektywy „dziesiątków lat pracy w samotności i dobrowolnie ograniczonych kontaktów" (Kijonka 2005: 27). Dzięki temu zasłużył się dla zbliżenia między narodami Polski i Niemiec. Odwołując się do idei misji, autorzy tekstów wspomnieniowych postrzegają pracę tłumacza literatury w kategoriach aksjologicznych: to coś znacznie więcej niż uprawianie określonego zawodu, to służba wyższym celom, kulturze, całemu społeczeństwu. Tłumaczenie podejmowane jest także ze względu na pasję, fascynację językiem, kulturą i literaturą albo stanowi odskocznię od trudnej rzeczywistości (np. Karl Dedecius zaczął tłumaczyć w łagrze).

Wbrew stereotypowemu wizerunkowi tłumacza samotnika, co piąty artykuł ukazuje tłumacza w kontekście intensywnych kontaktów towarzyskich i zawodowych. Tłumacze przekazują pałeczkę kolejnym pokoleniom, jak Rozka Štefan, która ,wykształciła w Słowenii dużą grupę entuzjastów polskiej literatury, dzisiaj znanych tłumaczy i naukowców" (Ostromęcka-Frączak 2011: 110), czy Ksenia Starosielska, której obce były „zazdrość i rywalizacja zawodowa (...), wychowała pokolenie młodych tłumaczy" (Nocuń 2017: 28). Troszczą się o pisarzy i redaktorów, jak Henryk Bereska, ,[w]ielki orędownik i przewodnik polskich pisarzy w Niemczech” (Kutz 2005: 129), czy Stanisław Barańczak i Maria Sten, służący pomocą rodakom przybywającym do Stanów Zjednoczonych i Meksyku. O konieczności zbudowania gęstej sieci kontaktów zawodowych wspomina Brockmann w cytowanym już artykule o Dedeciusie:

kariera literacka Mistrza nie mogłaby rozwijać się bez moralnego i finansowego wsparcia przyjaciół osobistych i instytucjonalnych, jak wydawnictwa Hanser, Suhrkamp, Fundacja Boscha, Volkswagena i innych. Dedecius był tego zawsze świadomy i nieustannie podkreślał wielkie znaczenie „zaplecza” literatury, które po części sam sobie stworzył, a po części było mu ono dane (Brockmann 2016: 101).

Wymienia się także zasługi tłumaczy dla popularyzacji innych twórców. Aktywni i uznani tłumacze dysponują ogromną siłą - jak Karl Dedecius mogą „kreować literackie wielkości” (Kuczyński E. 2016: 16), a ich obecność, jak w przypadku Henryka Bereski, ,nadawała rangę nawet błahej imprezie" (Mieszko-Wiórkiewicz 2005: 72). 
Wyłaniający się z tekstów wspomnieniowych wizerunek tłumacza literatury warto rozpatrzyć także w kontekście ich osiągnięć, wymienianych przez autorów nekrologów i wspomnień. Pod tym względem wyróżnić można trzy najbardziej reprezentatywne kategorie: nagrody i odznaczenia, prestiżowe kontakty czy wyrażone explicite uznanie za zasługi dla porozumienia między narodami. Zostały one przedstawione w tabeli 3.

Tabela 3. Liczba i procent artykułów odnoszących się do poszczególnych osiągnięć tłumaczy

\begin{tabular}{|l|c|c|c|c|}
\hline Osiągnięcia & $\begin{array}{l}\text { Liczba } \\
\text { artykułów }\end{array}$ & $\begin{array}{l}\text { Procent } \\
\text { artykułów }\end{array}$ & $\begin{array}{l}\text { Liczba } \\
\text { tlumaczy }\end{array}$ & $\begin{array}{l}\text { Procent } \\
\text { tlumaczy }\end{array}$ \\
\hline nagrody, odznaczenia & 19 & 38 & 15 & 43 \\
\hline kontakty & 19 & 38 & 13 & 37 \\
\hline $\begin{array}{l}\text { zasługi dla porozumienia } \\
\text { między narodami }\end{array}$ & 17 & 34 & 13 & 37 \\
\hline
\end{tabular}

We wszystkich kategoriach liczba artykułów była bardzo zbliżona odpowiednio 19, 19 i 17. Osiągnięcia powyższe wspominano w większości artykułów (64\%), przy czym jedna cecha pojawiła się w 24\% ogólnej liczby, dwie $-28 \%$, trzy - w $8 \%$ (w przypadku artykułów poświęconych Barańczakowi, Bray i Dedeciusowi). Wspominano między innymi nagrody translatorskie oraz odznaczenia państwowe. Nobilitujące dla tłumaczy były kontakty prywatne i zawodowe z innymi znanymi osobami, na przykład Ziemowit Fedecki przyjaźnił się z Wysockim i Okudżawą (Zadura 2009), cieszył się szacunkiem i zaufaniem Anny Achmatowej, Borysa Pasternaka i innych, a jego postać uwiecznili w swoich utworach Edward Stachura oraz Konstanty Ildefons Gałczyński (Kołodziej 2009). Stanisław Barańczak wspominany jest także w kontekście swoich kontaktów z noblistami:

Pamiętać należy, że nie byłoby wielkiego amerykańskiego sukcesu Wisławy Szymborskiej (a może i Nobla), gdyby nie przekłady Barańczaka (...). Staszek był niezastąpionym przewodnikiem - dzięki niemu mogłem nie tylko czytać, ale poznać osobiście Josifa Brodskiego i Seamusa Heaneya, a pośrednictwo ich tłumacza, przez obu uważanego za geniusza, otwierało u nich natychmiast kredyt zaufania i przyjaźni (Illg 2015: 87).

Zasługi dla porozumienia między narodami wymieniano szczególnie często w tekstach poświęconych Karlowi Dedeciusowi, nazywanemu 
„budowniczym mostów”, „pośrednikiem między kulturami” (Brockmann 2016: 97), ,jednym z głównych segmentów porozumienia obydwu narodów po drugiej wojnie światowej" (Kuczyński K. 2016: 10). Poza kontekstem polsko-niemieckim, wątek zasług dla porozumienia między narodami dotyczył relacji polsko-rosyjskich (postaci Ziemowita Fedeckiego, Jerzego Pomianowskigo, Kseni Starosielskiej czy Władimira Britaniszskiego), jak również polsko-japońskich (Yukio Kudo) czy polsko-meksykańskich (Maria Sten).

Oprócz wymienionych wyżej osiągnięć, status i znaczenie tłumacza podkreślano także liczbami: 200 tytułów przetłumaczonych przez Henryka Bereskę (Mieszko-Wiórkiewicz 2005) czy 300 autorów przekładanych przez Karla Dedeciusa (Kuczyński K. 2016). W kilku przypadkach przekłady określano jako genialne lub kongenialne, albo lepsze od oryginału.

Czy o zmarłych tłumaczach mówi się i pisze tylko dobrze? Biorąc pod uwagę przeanalizowany materiał, można odpowiedzieć, że zdecydowanie tak. Posługując się klasyfikacją wspomnień pośmiertnych opracowaną przez Stephana Steina, wszystkie teksty można zaliczyć do grupy wspomnień pozytywno-rzeczowych lub osobisto-emocjonalnych, których głównym celem jest oddanie szacunku zmarłemu i które zostały opracowane bądź to na podstawie ogólnodostępnych źródeł, bądź bezpośrednich kontaktów. Żadnego z artykułów nie można było przypisać do grupy tekstów krytyczno-negatywnych, a więc ujawniających bezpośrednie, potępiające podejście autora. Anna Hanus, omawiając typologię Steina, uzupełniła ją jednak o jeszcze jeden wariant: krytyczno-rzeczowy, odnoszący się do tekstów, w których potencjalnie negatywne opinie zostały zakamuflowane, przedstawione jako sądy innych lub zrównoważono je elementami pozytywnymi (Hanus 2015: 67). Jeśli weźmie się pod uwagę to uzupełnienie, można zauważyć, że w ośmiu artykułach wystąpiły pojedyncze uwagi o charakterze krytyczno-rzeczowym, przeważnie związane z charakterem (gadatliwość, nadmierna szczerość, arogancja czy złośliwość, patrz przykład 1 poniżej) lub wynikające ze zderzenia ideałów tłumacza z rzeczywistością: rezygnacja $\mathrm{z}$ ambicji ze względu na sytuację finansową, brak krytyki przekładu, świadomość niedocenienia i wyobcowania w środowisku (przykład 2):

Miał rację. Prawie zawsze miał rację, ale swoje racje wygłaszał w sposób tak arogancki i złośliwy, że najczęściej były nie do przyjęcia. (...) Znaliśmy się pięćdziesiąt lat; za naszej wspólnej młodości znajomi nazywali go Rudą Zarazą. (...) Był także mistrzem przyjaźni; jak to robił, nie zgłębiłam do tej pory, bo wszystkich swoich przyjaciół i znajomych permanentnie obrażał. Wyrażał się o wszystkich źle; w oczy i poza oczami (Katz 2007: 92 o Janie Goslickim). 
Czuł się outsiderem w towarzystwie thumaczy i poczucie to nie opuszczało go nigdy (...) Batko tłumaczył wiele, może zbyt wiele (...), przekład, po części wbrew jego woli, stał się jego zawodem i jedynym źródłem utrzymania. Spod jego pióra wychodziły przekłady książek zaskakujących, jakby z innych niż Zbyszkowe półek wzięte. Sam zresztą demaskował, nawet publicznie, literacką mierność niektórych przekładanych przez siebie autorów. (...) Nazwisko Batki mogło uwierzytelniać przekładaną przez niego literaturę, być gwarantem jakości nie tylko przekładu, ale także samego pisarstwa. Życie chciało inaczej (Jarniewicz 2008: 410).

Jak widać z powyższych przykładów, nie we wszystkich tekstach wspomnieniowych przestrzegano bezwzględnie tradycyjnej zasady de mortuis aut bene aut nihil. Dzięki temu czytelnik zyskuje obraz osoby z krwi i kości, mającej swoje zalety i wady, borykającej się z konkretnymi problemami, a sam nekrolog staje się bardziej wiarygodnym świadectwem życia i twórczości tłumacza. Można tylko się zastanawiać, czy takie odstępstwa od reguły stanowią wyjątek, czy zapowiedź nowego sposobu upamiętniania.

Nekrologi zamieszczane w analizowanych periodykach służą oddaniu hołdu zmarłemu, ,jednemu z nas", i utrwaleniu pamięci o nim, a w ten sposób integrują daną społeczność i tworzą pewien etos zawodu, przekazując wzory pożądanych zachowań. W tym miejscu warto zadać pytanie, na ile teksty wspomnieniowe odzwierciedlają wartości tworzące odrębny etos tłumacza literatury i jego pracy, a na ile stanowią odbicie pewnego ogólnoludzkiego ideału. $Z$ pewnością nie jest to kwestia łatwa do rozstrzygnięcia. $Z$ jednej strony, przedstawiona wyżej analiza cech i wartości uznawanych za najważniejsze w życiu polskich tłumaczy przyniosła rezultaty zbliżone do tych, które opisują Kinnier i inni (1994) w odniesieniu do psychologów amerykańskich. Z drugiej jednak strony łatwo wyobrazić sobie kontekst uwarunkowany ideologicznie, w którym liczą się zupełnie inne wartości. Dla przykładu, w cytowanym już artykule Klimowicz zauważa, że w nekrologach pisarzy radzieckich ,bardzo rzadko pisano (...) o przymiotach zmarłego niezwiązanych z obecnością w patologicznej przestrzeni społecznej”, zupełnie nie wspominając o takich ,egzotycznych pojęciach” jak „prawość”, „szlachetność” czy „dobroć” - w najwyższej cenie było oddanie „Wielkiej Sprawie” i ,właściwie zawierane znajomości i duchowi przewodnicy” (Klimowicz 1996: 182). Ponadto ścisłe rozgraniczenie cech „dobrego tłumacza” i cech „,dobrego człowieka” byłoby trudne, może nawet ryzykowne, gdyż zmuszałoby do odpowiedzi na pytanie o to, czy istnieją cechy typowe dla przedstawicieli danej profesji, oraz o to, czy zmarły postrzegany jest przez 
autora nekrologu przez pryzmat wykonywanego zawodu czy też niezależnie od niego. Bardzo interesujący jest w tym kontekście fragment nekrologu Piotra Szymanowskiego autorstwa jego przyjaciela, Leszka Kolankiewicza, który obrazuje, że powyższych kategorii nie można ostro i jednoznacznie rozgraniczyć, gdyż „bycie tłumaczem” i określone cechy charakteru, podejścia do świata wzajemnie się przenikają:

W tych kontaktach [z innymi] Piotr w jakimś sensie pozostawał thumaczem. To był najważniejszy rys jego podejścia do ludzi i do świata. Bez przerwy dopytywał, wszystkiego chciał dociec, wszystko wyjaśnić. Była w tym jakaś niepospolita otwartość, prawie dziecięca ciekawość. Chęć współodczuwania i wzajemnego zrozumienia. Była też wielka dokładność i rzetelność, które czyniły go tak sugestywnym. W tym swoim thumaczeniu wszystkiego i wszystkich był doprawdy niezmordowany (Kolankiewicz 2017: 219-220).

Zauważyłam we wstępie, że nekrolog jako dokument określonych czasów mówi niekiedy więcej o żywych niż o zmarłych. Jak więc teksty wspomnieniowe funkcjonują w obszarze kultury pamięci? Są to teksty o charakterze okazjonalnym - ich powstanie warunkuje fakt śmierci danej osoby, niezależnie od tego, czy publikuje się je w krótkim czasie po jej odejściu czy w związku z rocznicą (nekrologi rocznicowe). Charakteryzuje je konsytuacyjność, wynikająca zarówno z ich przynależności do grupy tekstów o śmierci, jak i z istnienia określonych sytuacji społeczno-komunikacyjnych, w które są wpisane. Jacek Kolbuszewski $(1997: 6,8)$ podkreśla także rolę norm kultury obyczajowej, które determinują zachowania funeralne właściwe danemu środowisku, oraz wskazuje, że nekrologi i wspomnienia, jako teksty o śmierci, dotyczące spraw ostatecznych, cechuje intencjonalnie i potencjalnie wysoki stopień zabarwienia emocjonalnego.

Analizowane w niniejszym artykule teksty wspomnieniowe są wpisane w ściśle określony kontekst komunikacyjny. Opublikowano je na łamach czasopism naukowych, literackich i kulturalnych, są więc - w odróżnieniu od prasy codziennej, adresowanej do ogółu społeczeństwa - czytane przez znacznie węższe, specyficzne grono odbiorców: specjalistów w dziedzinie filologii, literatury i kultury oraz elity intelektualne, zainteresowane życiem literackim i kulturalnym. O ile w gazetach dominują krótkie teksty o charakterze informacyjnym (obejmujące około tysiąca znaków i zbliżone charakterem do biogramu), które zwięźle wspominają zasługi i dokonania zmarłych tłumaczy, o tyle we wspomnianych wyżej periodykach są one znacznie bardziej rozbudowane, a ich najważniejszą funkcją jest już nie 
samo tylko informowanie o śmierci, lecz upamiętnianie życia i dokonań tłumacza. Można zaryzykować stwierdzenie, że pisma tworzą swego rodzaju forum dla żałobników, chcących wspominać i upamiętniać zmarłego członka społeczności. Wezwanie do współpamiętania kierowane jest do określonej grupy, związanej zawodowo z danym periodykiem, ale także do elit intelektualnych, a za ich pośrednictwem do całego społeczeństwa, co znacznie rozszerza społeczno-przestrzenny zakres pamięci o tłumaczach literatury.

W stworzonym na potrzeby artykułu korpusie teksty zazwyczaj występowały pojedynczo (jeden tekst upamiętniający jedną osobę), choć zdarzało się, że jednemu tłumaczowi poświęcano kilka tekstów w różnych czasopismach (np. nekrologi Henryka Bereski, Karla Dedeciusa czy Stanisława Barańczaka wystąpiły czterokrotnie). Sama obecność nekrologu na łamach periodyku naukowego, literackiego czy kulturalnego jest formą nobilitacji zmarłej osoby. O randze tłumacza i jego znaczeniu dla kultury, ale także o uznaniu w środowisku świadczyć mogą liczba takich tekstów, ich objętość czy miejsce usytuowania, osoba autora oraz fakt publikacji nekrologów rocznicowych. Z pewnością nie są to kryteria o charakterze bezwzględnym i wymiernym (pewną rolę mogą odgrywać choćby środowiskowe antypatie), jednak przykłady nekrologów poświęconych Dedeciusowi, Beresce czy Barańczakowi pokazują jasno, jakim poważaniem cieszyli się ci tłumacze w świecie kultury. Funkcję kommemoratywną mogą spełniać także inne praktyki przyjęte $\mathrm{w}$ danym środowisku, takie jak wydanie numeru specjalnego pisma, poświęcone w całości danemu tłumaczowi, publikacja tomu in memoriam lub powstanie nagrody jego imienia (niezależnie od tego, czy powstała za życia danej osoby, czy po jej śmierci, np. Nagroda im. Karla Dedeciusa, Nagroda za Twórczość Translatorską im. Tadeusza Boya-Żeleńskiego). Na takie formy upamiętnienia mogą jednak liczyć tylko najwybitniejsi i najbardziej zasłużeni tłumacze. W tym kontekście publikacja nekrologu jawi się jako najczęstsza praktyka kommemoratywna.

W analizowanym okresie (lata 2000-2017) tylko raz wystąpił nekrolog rocznicowy (dotyczył on Haliny Ogarek-Czoj, ,,matki polskiej koreanistyki”). Nekrologi rocznicowe są o tyle ciekawe, że pozwalają odpowiedzieć na pytanie, jak długo dana społeczność chce pamiętać zmarłą osobę. Niestety na podstawie zgromadzonych tekstów trudno jest rozstrzygnąć tę kwestię - analizowany materiał obejmował artykuły opublikowane w stosunkowo krótkim przedziale czasu (siedemnaście lat). Interesujące byłoby także porównanie nekrologów rocznicowych z nekrologami publikowanymi bezpośrednio lub krótko po śmierci tłumacza i przeanalizowanie ich wzajemnych relacji 
w kontekście kultury pamięci, co pozwoliłoby na przykład odpowiedzieć na pytanie, czy późniejsze nekrologi wprowadzają nowy ogląd postaci, czy też przywołują wspomnienia zawarte we wcześniejszych artykułach.

Autorzy nekrologów i wspomnień zwykle dawali się rozpoznać jako współpracownicy i/lub przyjaciele zmarłego. Teksty skupione głównie wokół analizy dorobku zmarłego, utrzymane w tonie oficjalnym, w których autor nie ujawniał (bezpośrednio ani pośrednio) swojego związku z tłumaczem, występowały znacznie rzadziej i obejmowały jedną trzecią korpusu. Osobisty, emocjonalny stosunek autora tekstu do thumacza znajdował swoje odzwierciedlenie zarówno w fakcie przytaczania anegdot czy opisu konkretnych sytuacji związanych ze zmarłym (co miało miejsce w co trzecim artykule), jak i w języku, na przykład Brockmann nazywa Dedeciusa „Mistrzem” (2016: 101), a Kolankiewicz kończy tekst poświęcony Piotrowi Szymanowskiemu słowami „Żegnaj, kochany przyjacielu!” (Kolankiewicz 2017: 221). Użycie pełnych ekspresji wyrażeń nie jest jednak zarezerwowane wyłącznie dla tekstów mających charakter osobistego wspomnienia. Świadczą o tym zaczerpnięte z niemieckojęzycznych mediów określenia Karla Dedeciusa przytoczone w jego nekrologu: „Wegbereiter und Institution”, „deutsch-polnischer Fährmann”, „Pontifex der Verständigung”, „Botschafter Polens im deutschen Sprachraum”, „Brückenbauer zwischen östlicher und westlicher Kultur”, „der bedeutendste Mittler Polens”, „der Grandseigneur der Poesien des slawischen Literaturraumes”, „Geliebter der polnischen Musen”, „Geburtshelfer und Doyen der polnischen Literatur im Deutschen", by wymienić tylko niektóre określenia (Kuczyński E. 2016: 13), mające uzmysłowić czytelnikom wielkie znaczenie zmarłego.

Co więcej, w niektórych tekstach wspomnieniowych autorzy rozszerzają krąg żałobników, kreując wspólnotę o szerszym zakresie niż konkretne grupy zawodowe czy elity intelektualne. Poprzez zastowanie inkluzywnego „my”, występują w imieniu wszystkich czytelników dzieł przełożonych przez tłumacza, jak na przykład w nekrologu Krystyny Krzemień-Ojak (,Zawdzięczamy jej dużo więcej niż przełożenie wielu podstawowych humanistycznych lektur klasycznych i najnowszych", Łukasiewicz 2016: 260) oraz Piotra Godlewskiego (,Zawdzięczamy mu przekłady tak fundamentalnych dzieł, jak Zbyt głośna samotność, Miasteczko, w którym czas się zatrzymat czy trylogia Wesela $w$ domu", Jagodziński 2011: 420). Mogą też reprezentować całe społeczeństwo polskie, jak w przypadku pożegnania Stanisława Barańczaka, wygłoszonego w czasie uroczystości pogrzebowych przez ówczesnego prezydenta RP Bronisława Komorowskiego i po 
autoryzacji opublikowanego w „Zeszytach Literackich”: „Jego przekłady dzieł Szekspira sprawiły, że Hamlet stał się naszym współczesnym, przemówił do nas językiem opisującym nasz własny świat. To on przybliżył nam angielskich poetów metafizycznych i wielu innych twórców poezji” (Komorowski 2015: 26).

Wśród funkcji pamięci społecznej socjolodzy wymieniają przekazywanie wartości i wzorów zachowań uznawanych przez daną grupę za ważne i godne utrwalenia (Szacka 2000: 54; Golka 2009: 17), tym samym wspomnienia współtworzą tożsamość społeczności. Nekrologi i wspomnienia pośmiertne tłumaczy literatury przedstawiają ich jako zaangażowanych w działania na różnorodnych polach, kompetentnych i pracowitych, dobrych przyjaciół, odznaczających się inteligencją i indywidualizmem, realizujących misję pośredniczenia między kulturami. Pisane przez ludzi nauki i kultury teksty wspomnieniowe, adresowane przede wszystkim do specjalistów w dziedzinie filologii, literatury i kultury oraz elit intelektualnych, a za ich pośrednictwem do całego społeczeństwa, opisują tłumaczy literatury nie w wąskim kontekście określonej grupy zawodowej, ale znacznie szerzej, jako twórców kultury. Warto przy tym raz jeszcze podkreślić, że cechy czy wartości najczęściej wymieniane przez autorów analizowanych tekstów nie charakteryzują wyłącznie tłumaczy. Wiele z nich spotyka się wszak także w tekstach wspomnieniowych poświęconych innym grupom zawodowym (zob. choćby wspominany już Kinnier et al. 1994). Niemożność ścisłego rozgraniczenia cech i wartości cenionych przez większość społeczeństwa oraz tych uznawanych za szczególnie ważne w życiu tłumacza z jednej strony utrudnia precyzyjne określenie etosu tego zawodu, z drugiej jednak podkreśla głęboko humanistyczny wymiar pracy przekładowej.

Utrwalenie sylwetek tłumaczy w nekrologach i wspomnieniach pośmiertnych wprowadza ich do pamięci społecznej i stanowi wezwanie do współpamiętania o nich jako o osobach współkształtujących kulturę, jest też oficjalnym uznaniem ich zasług i oddaniem im hołdu. Niezależnie jednak od tej formy upamiętnienia, pamięć o tłumaczach będzie żyła w przełożonych przez nich dziełach, wszak, jak zauważył jeden z najwybitniejszych tłumaczy XX wieku, Karl Dedecius: „Twórczość artystyczna jest ze swej istoty zmaganiem się ze śmiercią, rozpaczliwą próbą przeżycia, trwania, zyskania ludzkiej cząstki nieśmiertelności. Non omnis moriar, nie cały umrę - oto nadzieja wszystkich, wierzących i niedowiarków" (Dedecius 2013: 61). 


\section{Podziękowanie}

Bardzo dziękuję Panom Jackowi Napiórkowskiemu oraz Gabrielowi Kamińskiemu za pomoc $\mathrm{w}$ dotarciu do kilku nekrologów analizowanych $\mathrm{w}$ artykule.

\section{Teksty wspomnieniowe cytowane w artykule}

Bocheński J. 2007. Pożegnanie Marysi Brandysowej, „Zeszyty Literackie” 2, s. 187-188. Bocheński J. 2009. Joanna Guze (1917-2009), „Zeszyty Literackie” 1, s. 206-207.

Brockmann A. 2016. Schliemann polskiej poezji: wspomnienie o Karlu Dedeciusie, „Borussia” 57, s. 97-102.

Cirlić-Straszyńska D. 2009. Wolny ptak: wspomnienie o Aliji Dukanoviciu, „Twórczość. Miesięcznik Literacko-Krytyczny" 8, s. 123-125.

Dietzsch S. 2016. Krystynie Krzemień-Ojak (1932-2016), „Studia z Historii Filozofii” 1 , s. 11-12.

Illg J. 2015. Stanisław Barańczak (1946-2014), „Znak” 2, s. 84-87.

Jagodziński A.S. 2011. Piotr Godlewski (1929-2010), „Literatura na Świecie” 1/2, s. $420-425$.

Jarniewicz J. 2008. Po śmierci Zbyszka Batki, „Literatura na Świecie” 1/2, s. 408-411. Katz J. 2007. Mój przyjaciel Goślicki, „Znak” 6, s. 92-95.

Kijonka T. 2005. Henryk z Helgolandu: szkic do portretu Henryka Bereski, „Śląsk. Miesięcznik Społeczno-Kulturalny" 11, s. 24-28.

Kolankiewicz L. 2017. Pożegnanie, „Dialog” 2, s. 219-221.

Kołodziej R. 2009. Pan Ziemowit, „Nowa Okolica Poetów” 32, s. 240-243.

Komorowski B. 2015. Stanisław Barańczak 13 XI 1946 - 26 XII 2014, „Zeszyty Literackie" 1, s. 25-27.

Kubski G. 2006. Śp. ks. prof. Marian Wolniewicz - egzegeta, thumacz Biblii i wytrwaty popularyzator (1919-2005), „Ruch Biblijny i Liturgiczny” 2, s. 149-152.

Kuczyński E. 2016. Karl Dedecius 1921-2016, „Studia Niemcoznawcze” 57, s. 13-23. Kuczyński K. 2016. Pożegnanie Karla Dedeciusa, „Studia Niemcoznawcze” 57, s. 9-12. Kutz K. 2005. Leczyt pokiereszowana pamięć, „Zeszyty Edukacji Kulturalnej” 49, 128135.

Łukasiewicz K. 2016. Krystyna Krzemień-Ojak (1932-2016), „Kultura Współczesna. Teoria, Interpretacje, Krytyka” 2, s. 259-262.

Mieszko-Wiórkiewicz J. 2005. Piąte koło u wozu: wspomnienie o Henryku Beresce (1926-2005), „Odra” 11, s. 71-73.

Nocuń M. 2017. Pani Ksenia, „Tygodnik Powszechny” 50, s. 76-78.

Ostromęcka-Frączak B. 2011. Nestorka polonistyki stoweńskiej - Rozka Štefan (19132011), „Poradnik Językowy” 5, s. 106-117. 
Tomsia T. 2015. Stanisław Barańczak (1946-2014): dodawat otuchy, poruszat serca, „Topos” 1, s. 177-178.

Zadura B. 2009. Pan Ziemowit, Pan Ziemek, „Literatura na Świecie” 9/10, s. 424-426.

\section{Bibliografia}

Barańczak Stanisław, w: Encyklopedia PWN, https:/encyklopedia.pwn.pl/haslo/Baranczak-Stanislaw;3874274.html (dostęp: 26.07.2018).

Bzdoń J. 2009. Nekrolog jako gatunek tekstu. Uwagi o pokrewieństwie stylistycznym z biogramem, w: M. Kita (red.), Język - styl-gatunek, Katowice: Wydawnictwo Uniwersytetu Śląskiego, s. 48-58.

Dedecius K. 2013. Szkiełko tłumacza i oko poety. Eseje, Kraków: Universitas, s. 59-75.

Dilevko J., Gottlieb L. 2004. The Portrayal of Librarians in Obituaries at the End of the Twentieth Century, „Library Quaterly” 74(2), s. 152-180.

Fowler B. 2007. The Obituary as Collective Memory, London: Routledge.

Fowler, B., Bielsa E. 2007. The Lives We Choose to Remember: A Quantitative Analysis of Newspaper Obituaries, ,The Sociological Review” 55(2), s. 203-226.

Gackowski T., Łączyński M. 2009. Metody badania wizerunku w mediach, Warszawa: CeDeWu.

Golka M. 2009. Pamięć społeczna i jej implanty, Warszawa: Wydawnictwo Naukowe Scholar.

Gomez H. 2017. A Closer Look into the Life of Ordinary Translators through Unordinary Sources: The Use of Obituaries as a Microhistory Tool to Study Translators and Translation in Ohio, „New Voices in Translation Studies” 16, s. 55-83.

Hamann J. 2016. „Let us Salute One of our Kind”. How Academic Obituaries Consecrate Research Biographies, „Poetics” 56, s. 1-14.

Hanus A. 2015. Wspomnienie pośmiertne - gatunek o wielu obliczach? Spojrzenie z perspektywy badań germanistycznych, ,Słowo. Studia Językoznawcze” 6, s. 51-68. Heydel M. 2013. Gorliwość tłumacza. Przekład poetycki w twórczości Czesława Miłosza,

Kraków: Wydawnictwo Uniwersytetu Jagiellońskiego.

Hume J. 2000. Obituaries in American Culture, Jackson: University Press of Mississippi. Kinnier R.T., Metha A.T., Buki L.P., Rawa P.M. 1994. Manifest Values of Eminent Psychologists: A Content Analysis of Their Obituaries, „Current Psychology” 13(1), s. 88-94.

Klimowicz T. 1996. Przewodnik po współczesnej literaturze rosyjskiej i jej okolicach (1917-1996), Wrocław: Towarzystwo Przyjaciół Polonistyki Wrocławskiej.

Kolbuszewski J. 1997. Z głębokim żalem... O współczesnej nekrologii, Wrocław: Wydawnictwo Uniwersytetu Wrocławskiego.

Lachover E., Gavriely-Nuri D. 2011. Requiem to Nationalism? Shaping a Collective Israeli Identity through Obituaries, „GMJ: Mediterranean Edition” 6(1), s. 24-39.

Lindqvist Y. 2006. Consecration Mechanisms - The Reconstruction of the Swedish Field of High Prestige Literary Translation during the 1980s and 1990s, w: M. Wolf, 
(red.), Übersetzen - Translating - Traduire: Towards a "Social Turn"?, Münster: Hamburg-Berlin-Wien-London: LIT., s. 61-71.

Macfarlane B., Chan R.Y. 2014. The Last Judgement: Exploring Intellectual Leadership in Higher Education through Academic Obituaries, „Studies in Higher Education” 2, s. 294-306.

Miłosz Cz. 2006. Rozmowy polskie 1979-1998, t I, Kraków: Wydawnictwo Literackie. Sławiński J. (red.) 2002. Stownik terminów literackich, Wrocław-Warszawa-Kraków: Zakład Narodowy im. Ossolińskich.

Stanisław Barańczak, Culture.pl [online], https://culture.pl/pl/tworca/stanislaw-baranczak (dostęp: 26.07.2018).

Stein S., 2012. Nachrufe in der Presse. Textsortenprofil und Textsortenvariation, w: Ch. Grösslinger, H. Stöckl, G. Held G. (red.), Pressetextsorten jenseits der „News”: Medienlinguistische Perspektiven aufjournalistische Kreativität, Frankfurt/M.: Peter Lang, s. 125-138.

Szacka B. 2000. Pamięć społeczna, w: Z. Bokszański, A. Kojder (red.), Encyklopedia socjologii, t. III, Warszawa: Oficyna Naukowa.

Szymczak P. 2013. Czy da się żyć z tlumaczenia książek, http://piotrszymczak.info/czy-da-sie-zyc-z-tlumaczenia-ksiazek (dostęp: 26.07.2018).

Wasilewska A. 2012. Raport o kondycji tlumacza, http:/www.dwutygodnik.com/ artykul/3752-raport-o-kondycji-tlumacza.html (dostęp: 26 lipca 2018). 